\title{
Atributos físicos de um latossolo após o uso de doses de cama de frango acrescidas à adubação mineral
}

Diego Oliveira Ribeiro ${ }^{1,2}$, Gustavo Castoldi ${ }^{1}$, Haiany Dias Silva ${ }^{2}$, Thomas Jefferson Calvacante ${ }^{1}$, Joaquim Júlio de Almeida Júnior ${ }^{2}$, Lásara Isabella Oliveira Lima², Manuel Rodrigues Carballal ${ }^{2}$

Centro Universitário de Mineiros - UNIFIMES, Mineiros, GO. Instituto Federal Goiano - IF- GOIANO, Campus Rio Verde, Rio Verde, GO. E-mail: diego@unifimes.edu.br

\section{Resumo}

Resíduos oriundos da atividade agroindustrial têm sido comumente utilizados na agropecuária, isolados ou mesmo associados a fertilizantes minerais, podendo alterar as propriedades físicas do solo. $O$ presente trabalho objetivou avaliar os efeitos da utilização de fertilizantes minerais e combinados com cama de frango (CF) nos atributos físicos de um Latossolo. O experimento foi realizado em delineamento em blocos ao acaso, com 4 tratamentos e 5 repetições. Os tratamentos foram os seguintes: AM - Adubação mineral com $220 \mathrm{~kg}$ de 00-32-00 + $150 \mathrm{~kg}$ de $\mathrm{KCl} \mathrm{ha}^{-1} ; \mathrm{AM}+2 \mathrm{Mg} \mathrm{ha}^{-1} \mathrm{CF} ; \mathrm{AM}+4 \mathrm{Mg} \mathrm{CF} ; \mathrm{AM}+6 \mathrm{Mg} \mathrm{CF}$. Após o quarto ano de utilização de cama de frango associada a fertilizantes minerais, coletou-se amostras para determinação de atributos físicos do solo nas profundidades de 0 - 0,05 m, 0,05-0,10 m e 0,10 - 0,20 m. A associação de cama de frango, com adubação mineral, nas maiores doses, tende a elevar o volume total de poros de $0,45 \mathrm{~m}^{3} \mathrm{~m}^{-3}$ no tratamento $\mathrm{AM}$, atingindo $0,53 \mathrm{~m}^{3} \mathrm{~m}^{-3}$ no $\mathrm{AM}+4 \mathrm{Mg}$ ha ${ }^{-1} \mathrm{CF}$. A microporosidade obteve comportamento semelhante ao VTP, saindo de $0,32 \mathrm{~m}^{3} \mathrm{~m}^{-3}$ no AM, atingindo $0,40 \mathrm{~m}^{3} \mathrm{~m}^{-3}$ no AM +4 $\mathrm{Mg} \mathrm{ha}{ }^{-1} \mathrm{CF}$. Contudo o diâmetro médio ponderado de agregados, foram reduzidos de 2,95 $\mathrm{mm}$ no AM, para 2,43 mm no AM + $6 \mathrm{Mg} \mathrm{ha}{ }^{-1} \mathrm{CF}$. A porcentagem de macroagregados foram reduzidas com a adição de maiores doses de cama de frango ao fertilizante mineral.

Palavras-chave: agregação do solo; porosidade do solo; resíduos orgânicos.

\section{Physical attributes of a latosolo after the use of doses with poultry litter added mineral fertilization}

\begin{abstract}
Wastes from agroindustrial activity have been commonly used in agriculture, isolated or even associated with mineral fertilizers, and can alter the physical properties of the soil. This study aimed to evaluate the effects of the use of mineral and combined fertilizers with poultry litter (CF) on the physical attributes of a Cerrado Latosol. The experiment was conducted in a randomized block design with four treatments and five replicates. The treatments were as follows: AM - Mineral fertilization with $220 \mathrm{~kg}$ of $00-32-00+150 \mathrm{~kg}$ of $\mathrm{KCl} \mathrm{ha}{ }^{-1} ; \mathrm{AM}+2 \mathrm{Mg} \mathrm{ha}{ }^{-1} \mathrm{CF} ; \mathrm{AM}+4 \mathrm{Mg} \mathrm{CF} ; \mathrm{AM}+6 \mathrm{Mg}$ CF. After the fourth year of chicken litter use associated with mineral fertilizers, samples were collected to determine soil physical attributes at depths of $0-0.05 \mathrm{~m}, 0.05-0.10 \mathrm{~m}$ and $0.10-0.20 \mathrm{~m}$. The association of chicken litter, with mineral fertilization, at the highest doses tends to increase the total pore volume of $0.45 \mathrm{~m}^{-3} \mathrm{~m}^{-3}$ in the AM treatment, reaching $0.53 \mathrm{~m}^{-3} \mathrm{~m}^{-3}$ in the AM $+4 \mathrm{Mg} \mathrm{ha}^{-1} \mathrm{CF}$. The microporosity obtained a similar behavior to VTP, going out 0.32 $\mathrm{m} 3 \mathrm{~m}^{-3}$ in AM reaching $0.40 \mathrm{~m}^{-1} \mathrm{~m}^{-3}$ in $\mathrm{AM}+4 \mathrm{Mg} \mathrm{ha}{ }^{-1} \mathrm{CF}$. However the weighted average diameter of aggregates were reduced from $2.95 \mathrm{~mm}$ in $A M$ to $2.43 \mathrm{~mm}$ in $\mathrm{AM}+6 \mathrm{Mg} \mathrm{ha}^{-1} \mathrm{CF}$. The percentage of macroaggregates was reduced with the addition of higher doses the poultry litter to mineral fertilizer.
\end{abstract}

Keywords: soil aggregation; soil porosity; organic waste. 
Introdução

O Brasil, no ano de 2017, produziu aproximadamente 13 milhões de toneladas de carne de frango, sendo o estado de Goiás responsável por $7,15 \%$ desse total e $4,3 \%$ das exportações (ABPA, 2018). Essa elevada produção de proteína animal gera resíduos aviários, que frequentemente têm sido reaproveitados na atividade agropecuária (COSTA et al., 2009; PINTO et al., 2012; RIBEIRO et al., 2017; SILVA et al., 2018).

Os dejetos aviários produzidos, tais como a cama de peru ou a cama de frango, constituemse em adubo orgânico com características agrícolas favoráveis (VALADÃO et al., 2011), podendo ser utilizados em substituição parcial e/ou total a fertilizantes minerais (ANDREOLA et al., 2000; RIBEIRO et al., 2017; SILVA et al., 2018). $\mathrm{O}$ uso de tais adubos orgânicos pode resultar em melhorias nos atributos físicos do solo (GOMIDES; BORGES, 2014; RIBEIRO et al., 2016). A utilização de cama de frango como fertilizante para as culturas de feijão e milho em Nitossolo, por exemplo, resulta em alterações positivas, particularmente nas camadas superficiais, da macroporosidade, microporosidade e densidade do solo (ANDREOLA et al., 2000).

A estrutura do solo tem sido apontada como um bom indicador de qualidade do mesmo, intervindo em importantes processos, como retenção de água, infiltração de água, penetração radicular e sensibilidade à erosão (RESENDE et al., 2012; PEREIRA, et al., 2013). Portanto, manejos que atuem influenciando esses processos de forma positiva podem contribuir de forma indireta para o aumento da produtividade das culturas.

A utilização de cama de peru como fonte de fertilizante na cultura da cana-de-açúcar, resultou em aumento do volume total de poros e redução na densidade, na camada superficial do solo quando aplicados $12 \mathrm{Mg} \mathrm{ha}^{-1}$ (RIBEIRO et al., 2016). Efeitos semelhantes foram encontrados em um Latossolo cultivado com cana-de-açúcar adubada com cama de frango no sulco de plantio, impactando positivamente a porosidade do solo em camadas subsuperficias (GOMIDES; BORGES, 2014).

Efeitos distintos na agregação do solo também podem ser observados com a utilização de resíduos orgânicos (COSTA et al., 2008; ANDREOLA et al., 2000; PINTO et al., 2012; TROLEIS et al., 2017). Um Latossolo, no qual, se fez uso de cama de peru em pastagens não apresentou influencias na agregação do solo independente da profundidade analisada (PINTO et al., 2012). Também sob diferentes formas de adubação de pastagem com a utilização de resíduo orgânico e mineral, podem não influenciar a agregação do solo (TROLEIS et al., 2017). Por outro lado, a utilização de cama de peru em pastagem, pode obter efeitos positivos no índice de estabilidade de agregados, no entanto, esses efeitos não são observados em agregados maiores do que $2 \mathrm{~mm}$ de diâmetro em um Latossolo (COSTA et al., 2008). Andreola et al. (2000) observaram aumento na estabilidade de macroagregados quando utilizou-se adubação com esterco de aves.

Diversos estudos têm sido realizados com a utilização de resíduos orgânicos na atividade agropecuária, no entanto, ainda se faz necessário explorar melhor resultados sobre o uso continuado de tais resíduos, caracterizado por reaplicações. Nesse contexto, objetivou-se avaliar os atributos físicos em um Latossolo Vermelho cultivado com soja no verão e gramíneas no inverno, adubado com fertilizante mineral combinado ou não com cama de frango, após o quarto ano sucessivo de utilização.

\section{Material e Métodos}

O experimento foi desenvolvido na Fazenda Flores, localizada no $\mathrm{km} \mathrm{310,5}$, ao lado da BR 364, no município de Mineiros, GO. A região apresenta temperatura média anual de $24,2^{\circ} \mathrm{C}$ e precipitação pluviométrica média de $1.700 \mathrm{~mm}$. O clima predominante é quente, semiúmido e notadamente sazonal, com verão chuvoso e inverno seco, sendo classificado como "Aw", conforme a classificação de Köppen.

O solo da área experimental foi caracterizado como Latossolo Vermelho distroférrico, apresentando $390 \mathrm{~g} \mathrm{~kg}^{-1}$ de argila, $130 \mathrm{~g} \mathrm{~kg}^{-1}$ de silte e $480 \mathrm{~g} \mathrm{~kg}^{-1}$ de areia, na camada 00-0,2 m (EMBRAPA, 2013). A área experimental foi cultivada com a cultura da soja durante a safra verão, e com milheto no período de entressafra, durante os três primeiros anos (2013, 2014 e 2015). No quarto ano, o solo esteve submetido ao cultivo de soja na safra verão e milho para silagem durante a safrinha de inverno. As aplicações suplementares de cama aviária na área experimental iniciaram - se no ano de 2013. As aplicações das doses de cama de frango foram realizadas imediatamente antes do plantio da soja entre os meses de setembro e outubro. As quantidades de fertilizantes orgânicos e químicos 
dos tratamentos, foram constantes desde a instalação da área experimental até a coleta das amostras que ocorreu no início da estação chuvosa de 2017.

$O$ delineamento experimental adotado foi $o$ de blocos casualizados, com quatro tratamentos e cinco repetições. Cada parcela apresentou a dimensão de $20 \mathrm{~m}$ de largura por $10 \mathrm{~m}$ de comprimento, totalizando $200 \mathrm{~m}^{2}$. Os tratamentos foram constituídos pela adubação mineral (AM) com aplicação de $220 \mathrm{~kg}$ de 00-3200 e $150 \mathrm{~kg}$ de $\mathrm{KCl} \mathrm{ha}^{-1}$ acrescida, ou não, de adubação orgânica com cama de frango (CF): 1 $\mathrm{AM} ; 2-\mathrm{AM}+2 \mathrm{Mg} C \mathrm{CF} \mathrm{h}^{-1} ; 3-\mathrm{AM}+4 \mathrm{Mg} \mathrm{CF} \mathrm{ha}^{-1}$; e 4 - $\mathrm{AM}+6 \mathrm{Mg}$ há $^{-1} \mathrm{CF}$. Em todos os tratamentos, as aplicações dos fertilizantes, mineral e orgânico, foram realizadas sempre antes a semeadura da soja, à lanço, via esparramador de fertilizantes orgânicos tipo esteira de aço modulado.

$O$ resíduo aplicado ao solo foi oriundo de dejetos provenientes da criação de frango, com cama à base e maravalha, apresentando a seguinte composição (média das aplicações): $\mathrm{N}=$ 3,5 \%; $\mathrm{Mg}=1 \% ; \mathrm{K}_{2} \mathrm{O}=4,0 \% ; \mathrm{S}=0,45 \% ; \mathrm{P}_{2} \mathrm{O}_{5}=3,5 \%$; $\mathrm{Ca}=4,7 \%$; Carbono orgânico $=308 \mathrm{~g} \mathrm{~kg}^{-1}$; matéria seca $=70,2 \% ; \mathrm{pH}$ em água $=8,2 ; \mathrm{Co}=0,1 \mathrm{ppm}$; $\mathrm{Mo}=0,1 \mathrm{ppm}$.

As coletas para realização das amostras físicas do solo aconteceram no início da estação chuvosa de 2017, no final do mês de outubro, após o quarto ano de uso de cama de frango como adubação adicional à adubação mineral. Retiraram-se amostras nas profundidades DMP de $0-0,05 \mathrm{~m}, 0,05-0,10 \mathrm{~m}$ e $0,10-0,20 \mathrm{~m}$. Foram realizadas análises de densidade aparente do solo (Ds), macroporosidade (Ma), microporosidade (Mi), volume total de poros (VTP) e diâmetro médio ponderado de agregados (DMP). Para avaliação da massa de agregados, foi realizada uma separação em três classes: micro (< $0,25 \mathrm{~mm})$, meso $(0,25-2,00 \mathrm{~mm})$ e macroagregados ( $>2,00 \mathrm{~mm}$ ).

As análises de Ds, VTP, Ma e Mi foram realizadas a partir de amostras indeformadas de solo, coletadas utilizando-se um trado tipo Uhland e anéis metálicos de altura e diâmetro de $0,05 \mathrm{~m}$ (volume de $98 \mathrm{~cm}^{3}$ ), em dois pontos por parcela. A Ds foi determinada pela relação entre a massa de solo seco e o volume total do solo coletado. O VTP foi obtido pela diferença de massa entre o solo saturado e o solo seco (EMBRAPA, 2011). Para tal, as amostras de solo foram saturadas com água, pesadas, e então colocadas em estufa a 110 으 durante 48 horas para uma nova pesagem e obtenção de massa do solo seco. As análises de $\mathrm{Ma}$ e $\mathrm{Mi}$ foram realizadas em mesa de tensão de $6 \mathrm{KPa}$, conforme procedimentos descritos em Embrapa (2011).

A coleta de solo para a análise de agregados foi realizada retirando-se blocos de solo (amostras indeformadas) com auxílio de espátulas e uma pá reta, em pequenas trincheiras abertas em cada parcela. O solo coletado foi acondicionado em película de PVC e acomodado em potes plásticos. As amostras foram então levadas ao laboratório, destorroadas manualmente em pontos de fraqueza e secas à sombra. Posteriormente, o solo foi passado em jogo de peneiras com malha de $4 \mathrm{~mm}$ e $2 \mathrm{~mm}$, sendo que para avaliação utilizou-se o material retido nas peneiras de $2 \mathrm{~mm}$. Após isso, uma duplicata de 50 gramas foi colocada em papel filtro sobre um conjunto de peneiras com dimensões de 2, 1, 0,5, 0,25 e 0,125 mm. O nível da água foi ajustado de forma que os agregados contidos na peneira da parte superior foram umedecidos por capilaridade durante 4 minutos. Posteriormente os agregados foram retirados do papel filtro e transferidos diretamente para a última peneira. Após isso o aparelho de oscilação vertical foi ligado durante 4 minutos. 0 montante solo de cada peneira foi transferido para recipientes devidamente pesados e identificados, que foram levados à estufa, a $105^{\circ} \mathrm{C}$, até atingirem peso constante (EMBRAPA, 2011). Após realizada a separação das classes de agregados calculou-se o diâmetro médio ponderado (DMP, em $\mathrm{mm}$ ) conforme, Salton et al. (2012). Para avaliação da massa de agregados, foi realizada uma separação em três classes: micro $(<0,25$ $\mathrm{mm})$, meso $(0,25-2,00 \mathrm{~mm})$ e macroagregados (> $2,00 \mathrm{~mm}$ ).

Os resultados das análises físicas foram submetidos à análise de variância e as médias dos tratamentos comparadas em cada profundidade pelo teste de Tukey, a $5 \%$ de probabilidade. As diferentes profundidades analisadas foram consideradas como subparcelas. A comparação das médias dos tratamentos foi realizada com o auxílio do programa computacional Sistema para Análise de Variância - SISVAR (FERREIRA, 2011).

\section{Resultados e Discussão}

O volume total de poros (VTP) e a microporosidade sofreram influência do acréscimo de cama de frango à adubação mineral 
(Tabela 1). A densidade e a macroporosidade do solo, no entanto, não foram influenciadas pelas doses de cama de frango acrescidas à adubação mineral. O VTP sofreu influência apenas na camada de 0,05 a 0,1 m, no qual, obteve menor valor no tratamento AM. Os tratamentos com acréscimo de 2, 4 e $6 \mathrm{Mg} \mathrm{CF} \mathrm{ha-1} \mathrm{quando}$ comparados ao controle, foram superiores em $11,11 \%, 17,8 \%$ e $13,4 \%$, respectivamente. A microporosidade apresentou comportamento exatamente igual nas camadas de 0 a 0,05 e 0,05 a $0,10 \mathrm{~m}$, de modo que os menores valores foram obtidos com o tratamento AM, sendo os maiores no tratamento $\mathrm{AM}+4 \mathrm{CF}$ ha ${ }^{-1}$. Em relação a somente a adubação mineral (AM), houve elevação da microporosidade com o acréscimo de $4 \mathrm{Mg} \mathrm{CF} \mathrm{ha-1}$ à adubação mineral, sendo esta superior $25 \%$ e $18,75 \%$ nas camadas de 0 a 0,05 e 0,05 a $0,1 \mathrm{~m}$, respectivamente. A camada de 0,10 a $0,20 \mathrm{~m}$ não foi influenciada significativamente pelos tratamentos utilizados. Esses resultados corroboram os encontrados por Andreola et al. (2000), que ao estudarem os atributos físicos de um Nitossolo, sob influência da associação da adubação mineral à orgânica, verificaram redução na porcentagem de macroporos e aumento na de microporos, na camada de 0 a $0,10 \mathrm{~m}$.

Tabela 1. Atributos físicos de Latossolo Vermelho distroférrico sob sistema de sucessão de plantio (soja e gramíneas), submetido à adubação mineral e associada à cama de frango.

\begin{tabular}{|c|c|c|c|c|}
\hline \multirow{2}{*}{$\begin{array}{l}\text { Tratamentos } \\
\mathrm{Mg} \mathrm{ha}^{-1}\end{array}$} & Densidade & VTP $^{(1)}$ & Macroporos & Microporos \\
\hline & $\mathrm{Mg} \mathrm{m}^{-3}$ & & $-m^{3} m^{-3}-$ & \\
\hline
\end{tabular}
0 a $0,05 \mathrm{~m}$

$\begin{array}{cllll}\mathrm{AM} & 1,26^{\mathrm{ns}} & 0,50^{\mathrm{ns}} & 0,18^{\mathrm{ns}} & 0,32 \mathrm{~b} \\ \mathrm{AM}+2 \mathrm{CF} & 1,23 & 0,52 & 0,16 & 0,36 \mathrm{ab} \\ \mathrm{AM}+4 \mathrm{CF} & 1,37 & 0,55 & 0,15 & 0,40 \mathrm{a} \\ \mathrm{AM}+6 \mathrm{CF} & 1,33 & 0,55 & 0,19 & 0,36 \mathrm{ab}\end{array}$

$-0,05$ a $0,1 \mathrm{~m}$

$\begin{array}{cllll}\mathrm{AM} & 1,34^{\mathrm{ns}} & 0,45 \mathrm{~b} & 0,13^{\mathrm{ns}} & 0,32 \mathrm{~b} \\ \mathrm{AM}+2 \mathrm{CF} & 1,38 & 0,50 \mathrm{a} & 0,15 & 0,35 \mathrm{ab} \\ \mathrm{AM}+4 \mathrm{CF} & 1,43 & 0,53 \mathrm{a} & 0,15 & 0,38 \mathrm{a} \\ \mathrm{AM}+6 \mathrm{CF} & 1,44 & 0,51 \mathrm{a} & 0,16 & 0,35 \mathrm{ab}\end{array}$

$-0,1$ a $0,2 \mathrm{~m}$

$\begin{array}{cllll}\mathrm{AM} & 1,36^{\mathrm{ns}} & 0,47^{\mathrm{ns}} & 0,14^{\mathrm{ns}} & 0,33^{\mathrm{ns}} \\ \mathrm{AM}+2 \mathrm{CF} & 1,37 & 0,51 & 0,17 & 0,34 \\ \mathrm{AM}+4 \mathrm{CF} & 1,39 & 0,50 & 0,15 & 0,35 \\ \mathrm{AM}+6 \mathrm{CF} & 1,43 & 0,49 & 0,17 & 0,32\end{array}$

\footnotetext{
${ }^{\text {NS }}$ Não significativo. *Tratamentos seguidos de mesma letra não diferem estatisticamente pelo teste de Tukey ao nível de $5 \%$ de probabilidade; ${ }^{(1)}$ Volume Total de Poros. ${ }^{\text {NS }}$ not significant. ${ }^{*}$ Treatments followed by the same letter do not differ statistically by the Tukey test at $5 \%$ probability; ${ }^{(1)}$ Total pore volume.
}

Resultados semelhantes também foram observados por Ribeiro et al. (2016), notaram aumento da porosidade e redução da densidade do solo (camada 0 a $0,05 \mathrm{~m}$ ) com a aplicação em superfície de $12 \mathrm{Mg} \mathrm{ha}^{-1}$ na cultura da cana-de- açúcar. Do mesmo modo, Gomides e Borges (2014), verificaram efeitos positivos na porosidade do solo em camadas subsuperficiais, com aplicação de cama de frango no sulco de plantio da cana-de-açúcar, condizendo com os 
resultados encontrados neste estudo. De acordo com Kiehl (1979), valores de volume total de poros em solos argilosos variam entre 0,4 e 0,6 $\mathrm{m}^{3} \mathrm{~m}^{-3}$. Desse modo, todos os tratamentos e todas as profundidades analisadas apresentaram valores de VTP considerados adequados.

A forma de adubação, e a dose de cama de frango aplicada influenciaram os atributos de agregação do solo (Figura 1 e Tabela 2). A aplicação de cama de frango associada à adubação mineral nas doses de 4 e $6 \mathrm{Mg}$ ha $^{-1}$ reduziram o diâmetro médio ponderado (DMP) de agregados, sendo estes, respectivamente inferiores a utilização de somente fertilizante mineral em $10 \%$ e $16 \%$ na camada superficial ( 0 a $0,05 \mathrm{~m})$. Na camada de 0,05 a 0,10 m, o comportamento foi semelhante ao da camada superficial, de modo que a utilização de cama de frango associada à adubação mineral, na dosagem de $4 \mathrm{Mg}$ CF ha ${ }^{-1}$ apresentou o menor valor de DMP, sendo que os tratamentos com adubação mineral isolada e associada a $2 \mathrm{Mg} \mathrm{ha}^{-1}$ de cama de frango apresentaram valores de DMP superiores a utilização de fertilizante mineral associado à $4 \mathrm{Mg} \mathrm{ha}{ }^{-1}$, em $16 \%$ e $12 \%$, respectivamente. Já na camada de 0,10 a 0,20 m, as formas de adubação e as doses de cama de frango utilizadas não influenciaram os valores de diâmetro médio ponderado (DMP). Há umaa correlação positiva entre os estoques de carbono no solo com o DMP (SOUZA et al., 2017). Portanto, possivelmente os efeitos das adições de fertilizantes limitou-se principalmente nas camadas superficiais avaliadas nesse estudo $(0$ a $0,05$ e 0,05 a $0,10 \mathrm{~m})$. Na camada mais profunda avaliada $(0,10$ a $0,20 \mathrm{~m})$, a ausência de efeitos dos fertilizantes nos atributos de agregados pode ter ocorrido devido à aplicação dos mesmos terem sido em superfície e devido a ausência de revolvimento do solo.

Figura 1. Diâmetro médio ponderado de agregados (DMP). Médias seguidas por mesma letra em mesma profundidade não diferem entre si pelo teste de Tukey a 5\% de probabilidade. Aggregates mean weighted diameter (MWD). Averages followed by letter in the same depht do not differ from each other by the Tukey ar $5 \%$ probability.

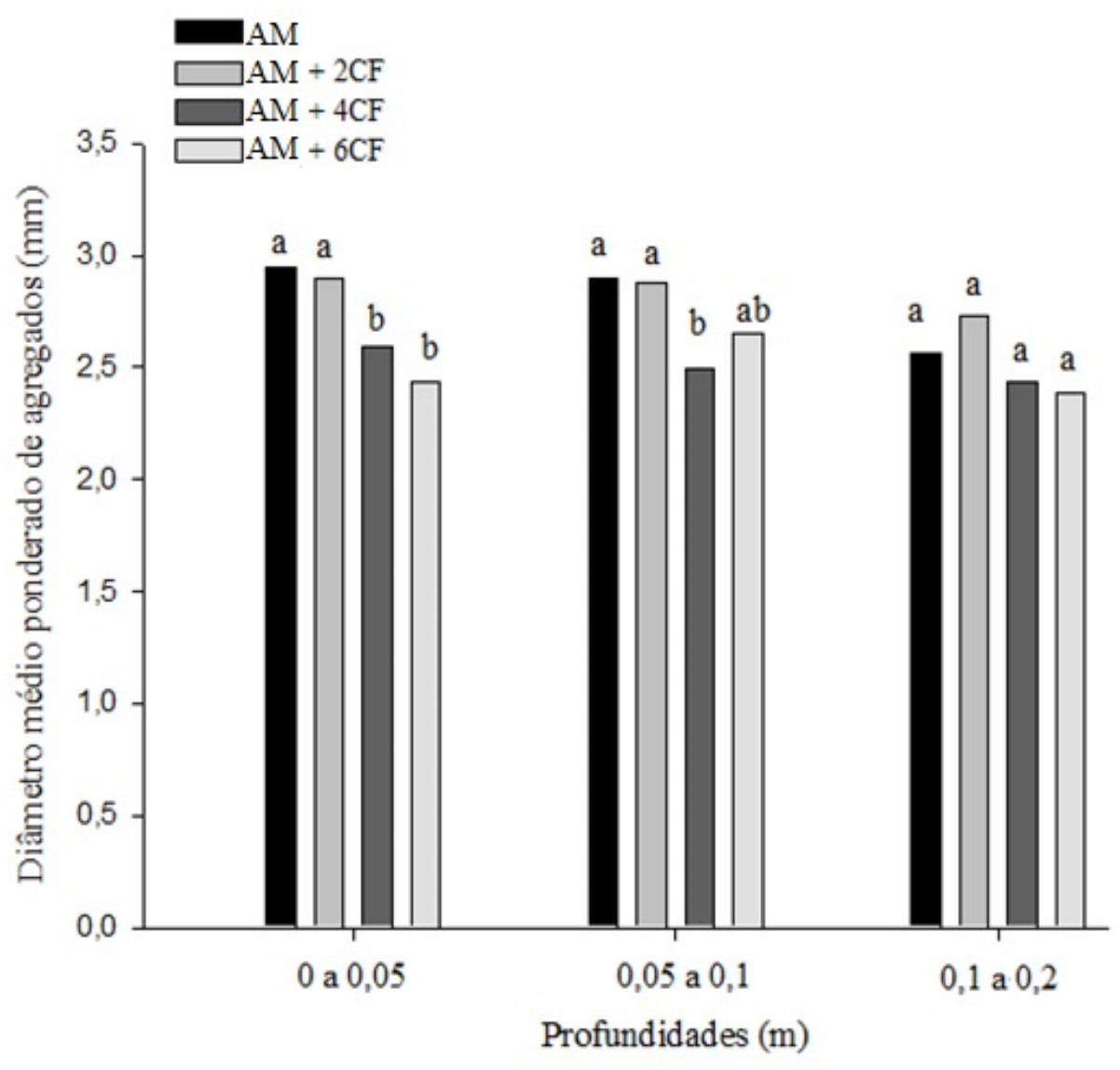


Diferentes sistemas de cultivos com a utilização de cama de frango crua e compostada verificaram redução do DMP, em diferentes profundidades $(0-0,10 ; 0,10-0,20$ e $0,20-0,30 \mathrm{~m})$ de um Latossolo Amarelo em relação à área de Cerrado, confirmando os resultados encontrados nesse estudo (VALADÃO et al., 2011). Esses mesmos autores ressaltam que a adição sucessiva de resíduos orgânicos ao longo do tempo no solo pode minimizar os impactos de sistemas intensivos de cultivo. Por outro lado, resultados distintos foram encontrados por Trolleis et al. (2017). Esses autores não verificaram efeitos na estabilidade de agregados com o uso de cama de peru quando comparado ao uso de fertilizante mineral e à ausência de fertilizante em pastagem de Urochloa brizantha, diferindo dos resultados encontrados nesse estudo.

Houve interferência dos diferentes tratamentos no tamanho de classes de agregados (macro, meso e microagregados) na camada de 0 a $0,05 \mathrm{~m}$ (Tabela 2). A proporção de macroagregados variou entre 60 a $84 \%$ nas profundidades e tratamentos. Na camada de 0 a $0,05 \mathrm{~m}$, a maior porcentagem de macroagregados foi obtida quando utilizados dos tratamentos AM e AM $+2 \mathrm{CF}$ ha $^{-1}$, sendo menores nos tratamentos $\mathrm{AM}+4 \mathrm{CF} \mathrm{ha}^{-1}$ e $\mathrm{AM}+6 \mathrm{CF} \mathrm{ha}^{-1}$. A porcentagem de macroagregados no AM foi superior em $16 \%$ e $21 \%$ aos tratamentos $A M+4 C F h^{-1}$ e $A M+6 C F$ $\mathrm{ha}^{-1}$. Comportamento praticamente inverso foi obtido na distribuição de mesoagregados e microagregados, apresentado maiores porcentagens de mesoagregados e microagregados nos tratamentos $\mathrm{AM}+4 \mathrm{CF}$ ha ${ }^{-1} \mathrm{e}$ $\mathrm{AM}+6 \mathrm{CF}$ ha $^{-1}$, sendo inferiores nos tratamentos $\mathrm{AM}$ e $\mathrm{AM}+2 \mathrm{CF} \mathrm{ha}^{-1}$.

Tabela 2. Distribuição de agregados estáveis em água (\%), em diferentes profundidades, em Latossolo Vermelho distroférrico sob sistema de sucessão de plantio (soja e gramíneas), submetido à adubação mineral e associada a cama de frango.

\begin{tabular}{|c|c|c|c|c|}
\hline \multirow{2}{*}{$\begin{array}{c}\text { Tamanho de } \\
\text { classes de } \\
\text { agregados }\end{array}$} & \multicolumn{4}{|c|}{$\begin{array}{c}\text { Tratamentos } \\
\mathrm{Mg} \mathrm{ha}^{-1}\end{array}$} \\
\hline & AM & $\mathrm{AM}+2 \mathrm{CF}$ & $\mathrm{AM}+4 \mathrm{CF}$ & $\mathrm{AM}+6 \mathrm{CF}$ \\
\hline & \multicolumn{4}{|c|}{0 a $0,05 \mathrm{~m}$} \\
\hline$<0,25 \mathrm{~mm}$ & $6,0 \mathrm{~b}$ & $6,0 \mathrm{~b}$ & $8,0 \mathrm{ab}$ & $12,0 \mathrm{a}$ \\
\hline $0,25 \mathrm{~mm}$ a $2,0 \mathrm{~mm}$ & $10,0 \mathrm{~b}$ & $13,0 \mathrm{~b}$ & $23,0 \mathrm{a}$ & $25,0 \mathrm{a}$ \\
\hline \multirow[t]{2}{*}{$>2 \mathrm{~mm}$} & $84,0 \mathrm{a}$ & $81,0 \mathrm{a}$ & $68,0 \mathrm{~b}$ & $63,0 \mathrm{~b}$ \\
\hline & \multicolumn{4}{|c|}{0,05 a $0,1 \mathrm{~m}$} \\
\hline$<0,25 \mathrm{~mm}$ & $6,0^{\text {ns }}$ & 4,0 & 8,0 & 7,0 \\
\hline $0,25 \mathrm{~mm}$ a $2,0 \mathrm{~mm}$ & $13,0 \mathrm{c}$ & $16,0 \mathrm{bc}$ & $29,0 \mathrm{a}$ & $23,0 \mathrm{ab}$ \\
\hline \multirow[t]{2}{*}{$>2 \mathrm{~mm}$} & $81,0 \mathrm{a}$ & $79,0 \mathrm{ab}$ & $63,0 \mathrm{c}$ & $69,0 \mathrm{bc}$ \\
\hline & \multicolumn{4}{|c|}{0,1 a $0,2 \mathrm{~m}$} \\
\hline$<0,25 \mathrm{~mm}$ & $10,0^{\mathrm{ns}}$ & 6,0 & 8,0 & 11,0 \\
\hline $0,25 \mathrm{~mm}$ a $2,0 \mathrm{~mm}$ & $24,0^{\mathrm{ns}}$ & 21,0 & 31,0 & 28,0 \\
\hline$>2 \mathrm{~mm}$ & $67,0^{\mathrm{ns}}$ & 73,0 & 60,0 & 60,0 \\
\hline
\end{tabular}

Ns Não significativo. ${ }^{*}$ Tratamentos seguidos de mesma letra na linha não diferem estatisticamente pelo teste de Tukey ao nível de $5 \%$ de probabilidade; ${ }^{(1)}$ Volume Total de Poros. ${ }^{\text {NS }}$ not significant. * Treatments followed by the same letter do not differ statistically by the Tukey test at $5 \%$ probability; ${ }^{(1)}$ Total pore volume

Já na camada de 0,05 a $0,10 \mathrm{~m}$, as classes de tamanho de agregados influenciadas pelas adubações e dosagens foram apenas os macroagregados e mesoagregados. A classe de macroagregados o tratamento AM obteve a maior porcentagem, e o $\mathrm{AM}+4 \mathrm{CF} \mathrm{ha}^{-1}$ a menor porcentagem, estando os tratamentos $\mathrm{AM}+2 \mathrm{CF}$ ha ${ }^{-1}$ e $A M+4 C F h^{-1}$ intermediários entre estes. Por outro lado, na classe de mesoagregados a maior porcentagem obtida foi no tratamento AM $+4 \mathrm{Mg} \mathrm{CF} \mathrm{ha}{ }^{-1}$, e o menor no tratamento mineral isolado. A camada de 0,10 a $0,20 \mathrm{~m}$ não foi 
influenciada pelos tratamentos propostos, não havendo diferença entre distintas adubações e dosagens.

Resultados semelhantes foram verificados, quando a adubação com cama de frango contribuiu para a redução na porcentagem de agregados maiores que $4,76 \mathrm{~mm}$ e redução da estabilidade de agregados com o a utilização de cama de frango na camada de 0,20 a $0,30 \mathrm{~m}$ de profundidade (ANDREOLA et al., 2000). Por outro lado, resultados distintos desse estudo foram encontrados por Pinto et al. (2012), em Latossolo. Esses autores não observaram aumento na distribuição de agregados com o aumento de doses de cama de peru em pastagem.

A união de macroagregados é realizada por diferentes agentes ligantes que são classificados como transitórios e temporários. Esses agentes são polissacarídeos derivados de microrganismos ou plantas e raízes e hifas fúngicas, respectivamente (TISDALL; OADES, 1982). A matéria orgânica particulada (MOP) atua como estabilizadora de macroagregados, e por ter maior labilidade é também mais decomponível (VEZZANI; MIELNICZUK, 2011). A MOP pode ser reduzida em doses inicias de cama de peru em área sob pastejo rotacionado, portando, podendo reduzir a agregação do solo (PINTO et al., 2012). Nos tratamentos em que foram aplicados as maiores doses de cama de frango (4 e $6 \mathrm{Mg} \mathrm{ha}^{-1}$ ), possivelmente o maior fornecimento de nutrientes e material orgânico oriundos da cama de frango, além de um possível aumento da quantidade de resíduos vegetais provenientes da soja nas maiores doses, podem ter contribuído para a decomposição da MOP, reduzindo o diâmetro médio ponderado de agregados (DMP) e também a proporção de macroagregados.

Sabe-se que a utilização em maiores doses de cama de peru pode elevar o $\mathrm{pH}$ do solo e também a saturação por bases (PINTO et al., 2012). A curto prazo, a elevação do $\mathrm{pH}$ do solo pode reduzir a agregação do solo por dissociar a matéria orgânica liberando cargas negativas e aumentar a dupla camada difusa (CASTRO FILHO; LOGAN, 1998). Desse modo, as maiores doses de cama de frango, o possível aumento de $\mathrm{pH}$ pode ter contribuído para uma redução inicial da agregação do solo. Uma maior agregação do solo é importante por afetar indiretamente o crescimento de plantas e a produtividade das culturas, pois influencia a infiltração e retenção de água, resistência do solo à compactação (BRAIDA et al., 2011). Portanto, sistemas de manejo que visem maior organização do solo em macroagregados são importantes para o crescimento vegetal.

\section{CONCLUSÃO}

Após quatro anos a adubação mineral e esta associada à cama de frango afetaram o VTP, a microporosidade e os atributos de agregação.

A maior porosidade total foi obtida quando ocorreu associação de fertilizantes minerais com a cama de frango. $\mathrm{O}$ tratamento $\mathrm{O}$ $\mathrm{AM}+4 \mathrm{CF}$, chegou a ser superior ao $\mathrm{AM}$ em aproximadamente $18 \%$ na camada de 0 a $0,05 \mathrm{~m}$.

A microporosidade seguiu comportamento semelhante ao VTP, sendo o $A M+4 C F$, superior em $25 \%$ e $18,75 \%$ em relação ao $\mathrm{AM}$ respectivamente nas camadas de 0 a $0,05 \mathrm{~m}$ e 0,05 a $0,10 \mathrm{~m}$.

Por outro lado, os atributos de agregação apresentaram comportamento distinto, sendo maiores os valores de DMP e macroagregados, quando a fonte de fertilizante utilizada foi à adubação mineral e está associada a menor dose de cama de frango. Os efeitos sobre a agregação foram observados nas profundidades de 0 até $0,10 \mathrm{~m}$.

\section{REFERÊNCIAS}

ANDREOLA, F.; COSTA, L. M.; OLSZEVSKI, N. Influência da cobertura vegetal de inverno e da adubação orgânica e, ou, mineral sobre as propriedades físicas de uma terra roxa estruturada. Revista Brasileira de Ciência do Solo, Viçosa, v. 24, n.4 p.857-865, 2000. https://doi.org/10.1590/S0100$\underline{06832000000400017}$

ASSOCIAÇÃO BRASILEIRA DE PROTEINA ANIMAL. Relatório Anual: exportações brasileiras de carne de frango e peru séries históricas. São Paulo, 2016.

BRAIDA, J. A.; BAYER, C.; ALBUQUERQUE, J. A.; REICHERT, J. M. Matéria orgânica e seu efeito na física do solo. Tópicos em Ciência do Solo, Viçosa, v. 7, p. 221-278, 2011.

CASTRO FILHO, C.; LOGAN, T. J. Soil agregation mechanisms affected by liming. In: WORLD CONGRESS OF SOIL SCIENCE, 16, 1998. Proceedings [...]. Montpellier, France, 1998. (CD ROM). 
COSTA, A. M.; BORGES, E. N.; SILVA, A. A.; NOLLA, A.; GUIMARÃES, E. C. Potencial de recuperação física de um latossolo vermelho, sob pastagem degradada, influenciado pela aplicação de cama de frango. Ciência e Agrotecnologia, Lavras, v.33, p.1991-1998, 2009. https://doi.org/10.1590/S1413$\underline{70542009000700050}$

COSTA, A. M.; RIBEIRO, B. T.; SILVA, A. A.; BORGES, E. N. Estabilidade de agregados de um Latossolo Vermelho tratado com cama de peru. Ciência e Agrotecnologia, Lavras, v.32, n.1, p.73-79, 2008. https://doi.org/10.1590/S1413$\underline{70542008000100011}$

COSTA, S. (Coord). A saga da avicultura brasileira. Rio de Janeiro: UBAPEF, 2011. 120p.

EMBRAPA. Manual de métodos de análise de solo. 2. ed. Rio de Janeiro: Centro Nacional de Pesquisa de Solos, 2011. 225 p.

EMBRAPA. Sistema brasileiro de classificação do solo. 3. ed. Brasília, 2013. 353 p.

FERREIRA, D.F. SISVAR: um programa para análises e ensino de estatística. Revista Symposium, v. 6, n. 1, p. 36-41, 2011.

GOMIDES, J. N.; BORGES, E. N. Atributos físicos de Latossolo cultivado com cana-deaçúcar e adubado com dejetos de animais de criação intensiva. Revista Agrotecnologia, Anápolis, v.5, n.1, p.33-49, 2014. https://doi.org/10.12971/2179-

5959/agrotecnologia.v5n1p33-49

PEREIRA, D. C.; WILSEN NETO, A.; NÓBREGA, L. H. P. Adubação orgânica e algumas aplicações agrícolas. Revista Varia Scientia Agrárias, Cascavel, PR, v. 3, n. 2, p.159-174, 2013.

PINTO, F. A; SANTOS F. L.; TERRA, F. D.; RIBEIRO, D. O.; SOUSA, R. R. J.; SOUZA, E. D.; CARNEIRO, M. A. C.; PAULINO, H. B. Atributos de solo sob pastejo rotacionado em função da aplicação de cama de peru. Pesquisa Agropecuária Tropical, Goiânia, v.42, n.3, p.254-262, 2012. https://doi.org/10.1590/S1983-

$\underline{40632012000300002}$
RESENDE, T. M.; MORAES, E. R.; FRANCO, F. O.; ARRUDA, E. M.; ARAÚJO, J. R.; SANTOS, D. S.; BORGES, E. N.; RIBEIRO, B. T. Avaliação física do solo em áreas sob diferentes usos com adição de dejetos animais no bioma cerrado. Bioscience Journal, Uberlândia, v.28, n.1, p.179-184, 2012.

RIBEIRO, D. O.; CARBALLAL, M. R.; SILVA, A. J.; LEAL, A. J. F.; CAETANO, J. O.; RODRIGUES, A. A.; VITAL, R. G.; PRADO, R. L. F.; SILVA, H. D.; MARTINS FILHO, M. B. Organic fertilization in soy farming in a tropical region. Australian Journal of Basic And Applied Sciences, p. 18-22, 2017.

RIBEIRO, D. O.; CARBALLAL, M. R.; SILVA, A. J.; SANTOS, T. E. B.; FERREIRA, L. L.; CUNHA, F, F. Produtividade de cana-de-açúcar e atributos de solo em função da aplicação de cama de peru. Revista de Ciências Agrárias: amazonian journal of agricultural and environmental sciences, Belém, v.59, n.3, p.259-264, 2016. https://doi.org/10.4322/rca.2215

SILVA, A. J.; CUNHA, F. F..; ROQUE, C. G.; SILVA, M. D. T.; RIBEIRO, D. O.; CARBALLAL, M. R. Replacement of liming and NPK fertilization with turkey litter in degraded areas grown with Urochloa decumbens. Semina: Ciências Agrárias, Londrina, v.39, n.02, p.467-476, 2018. https://doi.org/10.5433/1679-

$\underline{0359.2018 v 39 n 2 p 467}$

TISDALL, J. M; OADES, J. M. Organic matter and water-stable aggregates in soil. Journal of Soil Science, Hagertown, v.33, p.141-163, 1982. https://doi.org/10.1111/i.13652389.1982.tb01755.x

SALTON, J. C.; SILVA, W. M.; TOMAZI, M.; HERNANI, L. C. Determinação da agregação do solo: Metodologia em uso na Embrapa Agropecuária Oeste. Dourados: Embrapa, 2012. 8 p.

SOUZA, E.D.; CARNEIRO, M.A.; PAULINO, H. B. RIBEIRO, D. O. BAYER, C. B.; ROTTA, L. R. Matéria orgânica e agregação do solo após conversão de "campos de murundus" em sistema plantio direto. Pesq. Agropec. Bras., Brasília, v.51, n.9, p.1194-1202, set. 2016. https://doi.org/10.1590/s0100$\underline{204 \times 2016000900019}$ 
TROLEIS, M. J. B.; ROQUE, C. G.; BORGES, M. C. R. Z.; NOGUERIRA, K. B.; GOUVEIA, N. A. Estabilidade de agregados e teor de matéria orgânica em um Latossolo Vermelho sob Urochloa brizantha após a aplicação de cama de peru. Revista de Agricultura Neotropical, Cassilândia, v. 4, n. 1, p.83-87, 2017. https://doi.org/10.32404/rean.v4i1.1267

VALADÃO, F. C. A; MAAS, K. D. B.; WEBER, O. L. S.; VALADÃO JÚNIOR, D. D.; SILVA, T. J. Variação nos atributos do solo em sistemas de manejo com adição de cama de frango. Revista Brasileira de Ciência do Solo, Viçosa, v.35, n.6, p.2073-2082, $2011 . \quad$ https://doi.org/10.1590/S0100$\underline{06832011000600022}$

VEZZANI, F.; MIELNICZUK, J. O solo como sistema. Curitiba: Ed. dos Autores, 2011. 